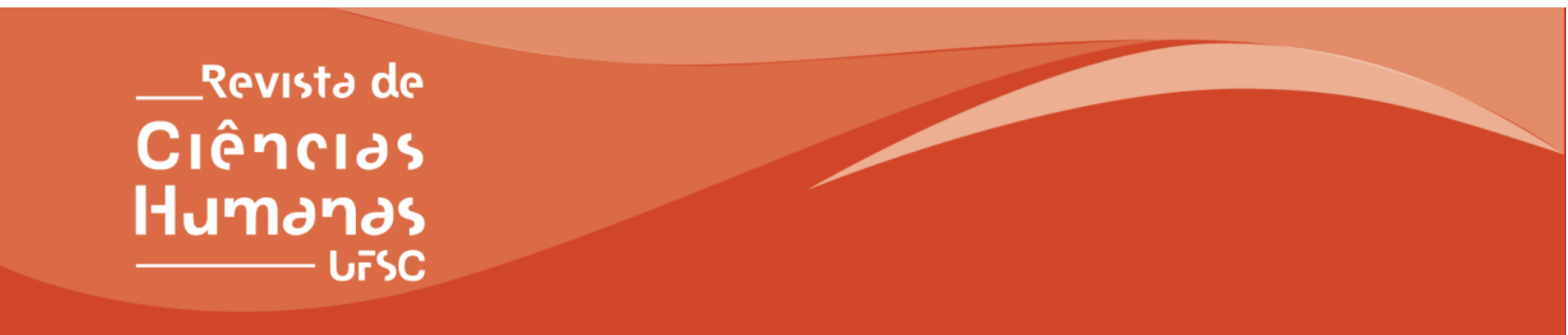

\title{
Rap e política: um debate teórico-metodológico
}

\section{Rap and politics: a theoretical-methodological debate}

\section{El rap y la política: un debate teórico-metodológico}

\section{Gabriel Passold}

\footnotetext{
${ }^{a}$ Doutorando em História na área de estética da arte, Universidade Federal de Uberlândia, Uberlândia, MG, Brasil - E-mail: gabrielpassold@hotmail.com
}

Resumo: Este artigo tem como objetivo problematizar alguns trabalhos que pesquisam a música do Rap, e propor outra abordagem. Esses trabalhos colocam o Rap no lugar de uma arte politizada. As artes, todavia, não operam com hierarquias, mas sim na invenção de outros lugares. Em contraponto a uma ideia de comunidade que funciona hierarquicamente, trabalhamos a partir do conceito de política no regime estético das artes, trabalhado por Jacques Rancière, onde não cabe definir o lugar das artes, mas sim analisar a arte em sua eficácia estética, pois qualquer arte tem o poder de fazer política, independente do seu conteúdo ou motivações. Entendemos que, pelo duplo poder das artes - em bagunçar as evidências de dominação e destinação dos corpos - podemos compreender esta época democrática. Propomos analisar essas cenas onde os corpos, antes destinados pelas hierarquias à obediência ou a arte politizada, participam de um processo de subjetivação política.

Palavras-chave: Arte. Política. Estética. Jacques Rancière.

Abstract: This paper aims to problematize some works on the research of Rap genre, and propose another approach. These works put Rap on a place of politicized art. The arts, however, do not operate with hierarchies, but inventing other places. In contrast to an idea of community that works hierarchically, we work from the concept of politics in the aesthetic regime of arts, as thought by Jacques Rancière, which does not to define the place of art, but analyzes it on their aesthetic effectiveness, because any art has the power to make politics, regardless of its contents or motives. We understand that, by the double power of arts - messing up the evidence of domination and destination of bodies - we can understand this democratic era. We propose to analyze these scenes where the bodies, at first destined by the hierarchies to obedience or politicized art, participate in a political subjectivity process.

Keywords: Art. Politics. Aesthetics. Jacques Rancière.

Resumen: Este artículo pretende problematizar algunos trabajos de investigación sobre el género Rap y proponer otro enfoque. Estas obras ponen al rap en un lugar de arte politizado. Las artes, sin embargo, no operan con jerarquías, sino que inventan otros lugares. En contraste con una idea de comunidad que funciona jerárquicamente, trabajamos desde el concepto de política en el régimen estético de las artes, como lo piensa Jacques Rancière, que no define el lugar del arte, sino que lo analiza en función de su efectividad estética, porque cualquier arte tiene el poder de hacer política, independientemente de su contenido o motivos. Entendemos que, por el doble poder de las artes, que confunde la evidencia de la dominación y el destino de los cuerpos, podemos entender esta era democrática. Nos proponemos analizar estas escenas donde los cuerpos, en un primer momento destinados por las jerarquías a la obediencia o al arte politizado, participan en un proceso de subjetividad política.

Palabras clave: Arte. Política. Estética. Jacques Rancière.

(c) $\overline{E Y}_{\mathrm{EY}}$ Direito autoral e licença de uso: Este artigo está licenciado sob uma Licença Creative Commons. Com essa licença você pode compartilhar, adaptar, para qualquer fim, desde que atribua a autoria da obra, forneça um link para a licença, e indicar se foram feitas alterações. 


\section{Como citar o artigo:}

PASSOLD, Gabriel. Rap e política: um debate teórico-metodológico. Revista de Ciências Humanas, Florianópolis, v.52, 2018. DOI: $10.5007 / 2178-4582.2018 .40825$

\section{INTRODUÇÃO}

Algumas produções acadêmicas brasileiras caracterizam a expressão musical do Rap como uma arte politizada. "Engajamento" e História do Rap no Brasil são vistos como concomitantes, e o grupo Racionais MC's é ajuizado muitas vezes como um exemplo desse tipo de caráter, como no caso do historiador Contier (2005) no artigo: “O Rap Brasileiro e os Racionais MC's". Trata-se, a partir desta constatação, de problematizar esse consenso que, ao atribuir determinados valores a uma expressão musical, contribui para o estabelecimento de hierarquias na arte. Tal conduta condiz com o regime representativo das artes, que, na esteira da "Poética" de Aristóteles (2011), entende a arte numa hierarquia de gêneros onde o Rap se enquadraria com uma forma de arte que, apesar de tecnicamente "limitada", teria seu valor justamente em seu caráter "engajado". Essa maneira de pensar a arte coincide com uma comunidade que funcionaria também pelas hierarquias, onde, por exemplo, há as pessoas de trabalhos manuais e as de trabalho intelectual, as "massas" que devem ser esclarecidas e os homens da palavra que seriam a vanguarda esclarecida. Em contrapartida, o conceito de regime estético trabalhado por Rancière (2005) nos fornece as bases para entendermos as artes de outra forma; não pelas hierarquias, mas por um viés democrático.

\section{A RUÍNA DAS HIERARQUIAS}

Demonstremos esse enquadramento a partir do qual problematizamos. Primeiro, em um trabalho que nos diz que "a questão central do rap está para além de músicas refinadas, de arranjos sofisticados e de letras altamente poéticas". Encontra-se uma maneira de enquadrar o Rap no rol da música brasileira em seu lugar, mesmo que de canção politizada. A hierarquia se revela, onde “importa pouco se os rappers produzem uma música pobre e se as letras são mal construídas”, pois o interesse nessa arte "consiste na constatação de que no rap que brota na temporalidade delimitada tem-se um amálgama de visões, sentimentos, concepções de mundo - mesmo que, por vezes, limitados e contingentes" (OLIVEIRA, 2011, p. 4). Vê se ai afirmação e negação do estilo musical ao mesmo tempo, numa tentativa de enquadrar a arte do Rap.

Esse lugar de "musica pobre", mas "politizada" é comum em abordagens acadêmicas com o Rap/Hip-Hop. Em outros trabalhos, vê se a mesma lógica: assim, mesmo com uma "linguagem não muito agradável para o público letrado", ou seja, considerando uma hierarquia de valor para a 
linguagem, “[...] o hip hop [...] tem contribuído para recuperar a vida de jovens que, caso não tivessem conhecido o hip hop, possivelmente adentrariam no mundo do crime" (SILVA, 2012, p. 233). Apesar de "não muito agradável" pra determinado público, o Rap ao menos guiaria o seu publico para a "salvação", tendo um papel moralista, onde ao denunciar a lógica do sistema contribuiria para "atingir um nível de conscientização mútua" (RIGHI, 2011, p. 321). Vê se aí a problemática "fórmula" representativa, que pela ideia da mímesis aristotélica, pressupõe, além das hierarquias, "um continuum sensível entre a produção de imagens, gestos ou palavras e a percepção de uma situação que empenhe pensamentos, sentimentos e ações dos espectadores" (RANCIÈRE, 2012a, p. 54). Tal fórmula não considera que os indivíduos são capazes de criar a sua própria performance com a arte que veem e, por isso, desconsidera a igualdade das inteligências.

Situemos historicamente as hierarquias. Já em Platão, conforme discute Rancière (1996), cada homem/mulher deveria cumprir seu papel na sociedade; por exemplo, ao homem do trabalho manual caberia realizar unicamente o seu trabalho, e aos aristocratas, homens de logos, investirem suas energias nas cenas políticas da pólis grega. Outro filosofo antigo, Aristóteles, ainda justifica a divisão dos lugares de cada um, separando os homens que possuem logos - que podem se comunicar inteligivelmente - dos homens e mulheres que possuem apenas à phoné: a palavra sem lógica, passível de exprimir apenas dor, raiva, impossibilitando-os de participar das cenas políticas. O povo estaria fadado a sua atividade de cada dia, enquanto os aristocratas gregos atuariam nas cenas políticas. Nesse conceito de democracia grego, há um erro de contagem, pois esta abrange o povo desde que este esteja fora das discussões da polis, o que bloqueia assim sua participação nas cenas políticas.

Ainda para Platão (2014), no segundo livro da República, uma atividade em particular seria nociva para o funcionamento da democracia: a arte, pois onde cada um deveria estar em seu lugar na engrenagem democrática, o artista quando atua não está. $\mathrm{O}$ ator, por exemplo, realiza um duplo papel ao atuar e imitar outro ofício em sua cena, uma vez que se coloca a imitar no palco atividades que não conhece bem, age fora de seu lugar e, assim, cria cenas de dissenso. Para Platão, a atividade artística prejudicava o melhor funcionamento da democracia consensual na República, pois nessa, outro arranjo das coisas é possível, proposto por alguém que não realiza suas atuações com o mesmo “domínio" do especialista.

Conforme Platão já ensinava na República, e que entendemos ser a maneira como ainda são concebidas as democracias consensuais do século XXI, incluindo parte da produção acadêmica brasileira; por essa "lógica [...], que distribui os corpos no espaço de sua visibilidade ou de sua invisibilidade e põe em concordância os modelos do ser, os modos do fazer e os modos do dizer que convêm a cada um"; propomos outra lógica, "que suspende essa harmonia pelo simples fato de 
atualizar a contingência da igualdade [...] dos seres falantes quaisquer.” (RANCIÈRE, 1996, p. 4041). Tal ruptura da ordem que distribui os lugares de cada um na República caracteriza a política. Entendemos que a política começa justamente, nesse obstáculo ao bom funcionamento da democracia denunciado por Platão, começa

[...] quando seres destinados a permanecer no espaço invisível do trabalho que não deixa tempo para fazer outra coisa tomam o tempo que não têm para afirmar-se coparticipantes de um mundo comum, para mostrar o que não se via, ou fazer ouvir como palavra a discutir o comum aquilo que era ouvido apenas como ruído dos corpos (RANCIÈRE, 2012a, p.60).

Definir, através de produções acadêmicas, o que é e o que faz o Rap, não é nosso foco: limitamo-nos a afirmar que a música, em si, faz política. Apresentamos outra proposta de pesquisa com a arte, que diverge do modelo representativo: analisá-la pelo estético, e não pela tradição da ordem policial que coloca os corpos nos seus lugares, mas em um sentido democrático, onde se considera o poder de qualquer um, de, através do estético, tocar na política, independente das intenções ou do conteúdo discursivo presente na arte.

Em contraponto ao que se caracteriza como juízo de valor que constitui categorias na música; a partir do conceito de regime estético das artes, não nos cabe definir o lugar de uma expressão artística, pois as artes há algum tempo já não operam por tais hierarquias. Assim, quando há um foco de pesquisas sobre a música que procura instituir de alguma maneira, categorias, estas participam, ao enquadrar essas artes, de uma ordem policial, onde, para o bom funcionamento da democracia, cada um deve se ocupar de seu ofício, cada artista com a sua arte. Nossa proposta de abordagem não considera o primado da palavra e das intenções dos artistas, como no regime representativo. Tudo o que possa participar da estética das obras, as sonoridades, os vídeos, as capas de álbuns, imagens que possam ser notadas em um verso, numa rima, ou mesmo no conjunto de um álbum é passível de ser analisado a partir do regime estético.

Entendemos que a música faz política, o que não significa prever o efeito que causa nos espectadores, e muito menos definir o que é politizado e o que não é. A arte no regime estético é um exemplo, antes de tudo, de que todos possuem a mesma manifestação de inteligência e o Rap é uma demonstração de como qualquer um pode fazer uso do logos nas cenas da polis e correr o risco de participar de cenas de dissenso na democracia consensual. Consideramos que o Rap faz isso, não necessariamente, e não somente por seu conteúdo discursivo, mas antes ao demonstrarem, fazendo arte, que o poder não tem "dono", mas perpassa seus corpos. Constroem seu mundo dia após dia, e a arte torna evidente que, denominá-los “excluídos” (CONTIER, 2005) nunca foi apropriado, a não ser para continuar descrevendo e afirmando a dominação indefinidamente até o fim dos tempos. Entendemos, por outro lado, que a política pode estar em qualquer lugar, na música de Rap dos 
Racionais MC's ou na obra da artista Valesca Popozuda que, por exemplo, em sua performance (figura 1), se apropria de elementos historicamente vinculados aos "Donos do poder" (CONTIER, 2005).

\section{Figura 1: A poderosa Valesca e a ave de rapina}

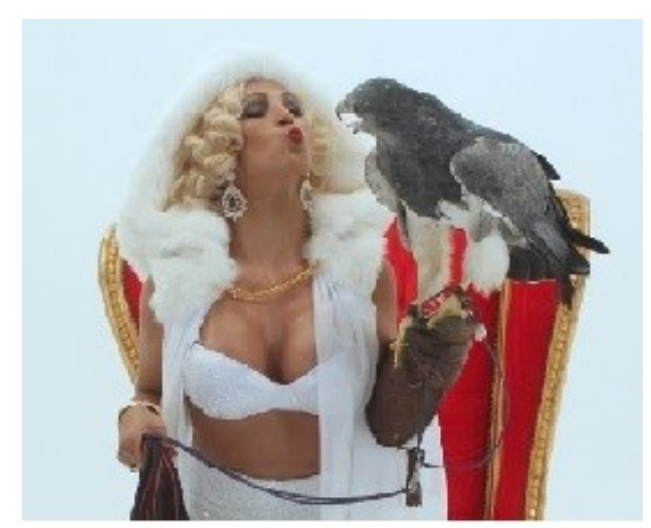

Fonte: VALESCA POPOZUDA: Beijinho no ombro (Official Music Video) (2013).

Podemos notar que, quaisquer formas de enquadramento para as artes não são critérios a priori no interior do estado estético. Pensamos ser mais apropriada uma relação de amadorismo com as artes, no sentido de que amadorismo é uma posição tanto teórica quanto política e “[...] que recusa a autoridade dos especialistas, sempre a reexaminar o modo como as fronteiras entre suas áreas se traçam na encruzilhada das experiências e dos saberes" (RANCIÈRE, 2012b, p. 16). Define-se, pois, o regime estético das artes, como "aquele que propriamente identifica a arte no singular e desobriga essa arte de toda e qualquer regra específica, de toda hierarquia de temas, gêneros e artes" (RANCIÈRE, 2005, p. 49).

Antes de tudo, é pela vontade que se inscreve o poder de qualquer um. Medir ou enquadrar tal poder não é interessante, mas sim admitirmos a rede de relações de poder que o manifesta, pois tal democracia está inscrita por todos os lados, desde movimentos de desobediência, como greves, nas inscrições artísticas, ou mesmo nas diferentes maneiras como as pessoas produzem sua existência. Mesmo que nos propomos a trabalhar a partir de um enquadramento na arte sonora, que é o Rap, pretendemos superar tal enquadramento, pois não se trata de afirmar esse "estilo" musical, correndo o risco de reforçar o seu lugar na democracia consensual; antes, pensamos que a Música funciona como um dispositivo que, através de seu duplo poder de bagunçar as evidências da "dominação" e destinação dos corpos, anuncia que a revolução democrática está ao alcance de qualquer um. Também não se trata de analisar a totalidade de um "estilo" musical, o que deve ser levado em consideração em cada expressão artística é a sua eficácia estética. 


\section{ESPECTADORES EMANCIPADOS}

"A música é uma arma. Se ela tem esse poder de mover o sistema, tem também o poder de elucidar" (CONTIER, 2005, p. 1). Antes do início do artigo de Contier, consta esta frase do produtor Milton Sales. Em outro trabalho, os artistas são tidos como "porta-vozes das periferias brasileiras", e a arte funcionaria como "instrumento de denúncia e de crítica ao contexto social e político". Fala-se até em um "poder" que esse estilo assumiria "sobre as populações marginalizadas" (RIGHI, 2011, p. 321) através de suas letras. Não se trata aqui de negar esse poder, mas discutir a pretensão da Academia, pois o "poder de elucidar" é evidente que existe; no entanto, não reside nas falas dos Racionais, nem em qualquer outro artista, mas localiza-se, antes, em qualquer indivíduo que tenha sentidos. Os Racionais, Caetano ou Valesca, ou então, a música; são armas muito eficientes para mover o sistema a algum lugar diferente, ao menos concordamos neste aspecto. Entretanto, não são as intenções dos artistas que determinam esse movimento, mas o sentimento que a eficácia estética de suas obras estimula. A pretensão em definir esse movimento é problemática, pois na tentativa de “elucidar" a arte, corre-se o risco de justamente fazer o contrário, enquadrando-a e, portanto, dandolhe uma imagem “oficial”. As artes, pelo menos há cerca de duzentos anos, não mais se delimitam, pois não se esgotam suas riquezas, entendendo riqueza como riqueza sensível, onde, desde que continuem nascendo seres humanos, haverá sempre uma nova maneira de perceber, e, portanto, de reinventar aquela mesma arte que outros já sentiram.

Analisamos as artes de maneira que atores e espectadores se confundem, pois estes, em contato com alguma arte, como a música, exprimem o seu próprio sentido sobre tais expressões, em última análise, a arte que vemos não é somente a que o artista fabricou, mas, além disso, trata-se de uma nova arte que construímos. A partir dessa abordagem, definir o Rap "como um amplo movimento global e massivo que procura 'falar' pelos excluídos sociais" (CONTIER, 2005, p. 11) parece-nos uma conclusão um tanto apressada, visto que não há uma energia de transformação ou mesmo conscientização que perpassaria os corpos de acordo com suas "boas" intenções, como pressupõe essa ideia exposta por Contier.

Uma vez que, ao olhar uma obra de arte, somos "espectadores distantes e intérpretes ativos do espetáculo", é imprescindível que desconsideremos essa oposição entre o artista e o espectador, pois a criação nas artes é livre, oposta à lógica do pedagogo embrutecedor; que considera a transmissão direta e fiel da expressão artística onde há sempre "alguma coisa, um saber, uma capacidade, uma energia que está de um lado - num corpo ou numa mente - e deve passar para o outro". Não há uma mente criativa que produz arte e outra que simplesmente a recebe, muito menos uma mente "politizada" que transmite consciência sobre a realidade. Nesse processo, não se opõe a ação ao olhar 
passivo, pois é uma relação em que estão em jogo duas inteligências iguais, não cabendo a nós distingui-las. Qualquer espectador, ao observar uma arte, parte de sua história, para então compor “seu próprio poema com os elementos do poema que tem diante de si” (RANCIÈRE, 2012a, p. 1718). Não existe fronteira que separa o que é canção que politiza e canção que diverte, pois a música mais despretensiosa em termos de "crítica ao sistema capitalista" (CONTIER, 2005, p. 7) pode ser tão ou mais política que a música que, aparentemente se propõe a fazer tal crítica.

O Rap, por sua vez, ainda não é entendido como "a arte" emancipadora e muito menos possui a priori essa característica. Qualquer arte, ou mesmo qualquer aspecto da vida, pode corroborar para a emancipação. O Rap, com suas “denúncias”, também não dá exemplos de como superar os "Donos do Poder", seria esse o caso no regime representativo das artes, com a representação verossímil da realidade que Aristóteles prescrevia em suas reflexões sobre a arte grega, onde a arte transmite mensagens e oferece "modelos" a seguir. Ali onde alguns veem a máquina que a todos domina como faz parte da produção acadêmica - existem pessoas construindo novas existências. O seguinte trecho de Rancière (2013), de seu livro $O$ mestre ignorante, nos traz essa relação entre artista e emancipação, ponto essencial de nossa pesquisa:

A lição emancipadora do artista, oposta termo a termo à lição embrutecedora do professor, é a de que cada um de nós é artista, na medida em que adota dois procedimentos: não se contentar em ser homem de um ofício, mas pretender fazer de todo trabalho um meio de expressão; não se contentar em sentir, mas buscar partilhá-lo (RANCIÈRE, 2013, p. 104).

Com os elementos sensíveis que tem à disposição em seu mundo, o artista da música participa dessa partilha do sensível, pois imprime em sua arte as suas apropriações desse mundo, o que acaba por construir indefinidamente novos lugares, novos mundos.

Por emancipação, conceito que perpassa nossa abordagem, compreendemos através de Rancière:

A mesma inteligência faz os nomes e os signos matemáticos. A mesma inteligência faz os signos e os raciocínios. Não há dois tipos de espíritos. Há desigualdade nas manifestações da inteligência, segundo a energia mais ou menos grande que a vontade comunica à inteligência para descobrir e combinar relações novas, mas não há hierarquia de capacidade intelectual. É a tomada de consciência dessa igualdade de natureza que se chama emancipação, e que abre o caminho para toda aventura no país do saber (RANCIÈRE, 2013, p. 49).

\section{A ORDEM POLICIAL E A DEMOCRACIA NO REGIME ESTÉTICO DAS ARTES}

Quando utilizamos o conceito de democracia, não estamos nos referindo aos Estados democráticos e sua política oficial; a política não consiste na produção de sujeitos que dão voz aos anônimos, do "consenso" entre os diferentes grupos que compõem o todo. Essa "democracia consensual" não muda a distribuição sensível quando destina cada um ao "seu lugar". Inversamente, 
a democracia entendida no interior do regime estético, é essencialmente produtora de cenas de dissenso, portanto, caracterizando cenas políticas. Os termos de Rancière nos indicam que "a política própria à arte no regime estético consiste na elaboração do mundo sensível do anônimo, dos modos do isso e do eu, do qual emergem os mundos próprios do nós político" (RANCIÈRE, 2012a, p. 65), mesmo que não seja possível medir esse efeito na construção do mundo.

Os termos antônimos "política" e "polícia", empregados por Rancière, indicam-nos o procedimento: não pretendemos mapear onde há e onde não há indícios de política ao definir o que é o Rap: isto seria submeter as capacidades políticas de cada um por meio do poder policial, que circunscreve a capacidade de cada um à sua "época" e "lugar". A política funciona quando se rompem as evidências sensíveis dessa ordem "natural” que, desde a antiguidade, destina os indivíduos e os grupos a este ou aquele ofício, "à vida pública ou à vida privada, votando-os sobretudo a certo tipo de espaço ou tempo, a certa maneira de ser, ver e dizer" (RANCIÈRE, 2012a, p. 60). Pode haver política em qualquer lugar onde há esse movimento que bagunça as evidências dessa ordem contingente. Através de uma discussão que perpassa a arte, na música, evidenciam-se cenas dessa bagunça das evidências sensíveis que destinam os corpos aos seus lugares. A garrafa e taça de champanhe na capa do álbum dos Racionais contracenam com as "calças largas" do hip hop. Esse detalhe nos remeteria mais aos "donos" do que aos "excluídos" do poder, e não é por isso que os Racionais perdem sua pretensa "pureza" de arte contestatória, mas é justamente nesses momentos que podemos perceber a política do regime estético (figura 2).

Figura 2: O poder dos Racionais MC's

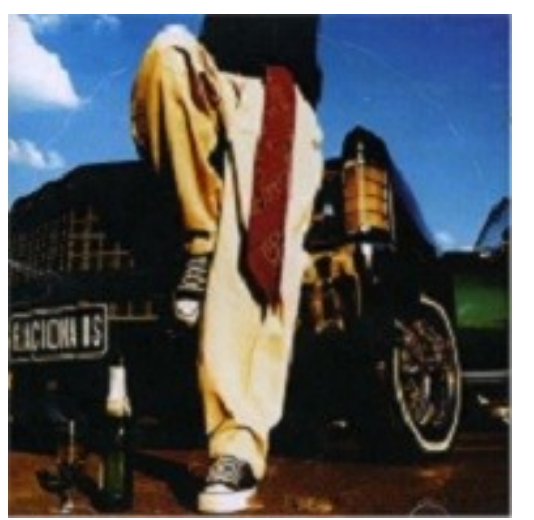

Fonte: MITTELDORF, Klaus. Fotografia capa do álbum. Racionais Mc's: Nada como um dia após o outro dia (2012).

A música participa da democracia, como já foi dito, não a partir da sua versão "oficial" das instituições, pois a "identificação absoluta da política com a administração do capital não é mais o segredo vergonhoso que as 'formas' da democracia viriam mascarar”, mas está aí para ser visto por qualquer um. Vê-se, costumeiramente, a “identificação da 'forma' democrática com a prática administrativa de submissão à necessidade mercantil” (RANCIÈRE, 1996, p. 114-115). Nos estados 
democráticos, não há política quando a administração da abundância se torna idêntica à administração da crise. Todavia, na música, fora dessa prática administrativa, o "povo" faz política, pois a qualquer momento são forjadas "formas de um senso comum polêmico" (RANCIÈRE, 2012a, p.75). Entendemos que o Rap, partícipe da arte em seu regime estético, atua na criação de maneiras de viver, na produção de subjetividades políticas por aqueles cuja natureza, segundo os Estados democráticos, os destinaria à execução exclusiva de seu trabalho, ou então, à execução de suas expressões artísticas de "matizes contestatórios" (CONTIER, 2005, p. 11).

Além disso, nessas obras de arte, há algo mais do que um “[...] caráter unicamente defensivo na luta das minorias - 'somos vítimas, ninguém reconhece nossos direitos"”, ou então os “despossuídos sociais" que agora "denunciam em suas canções problemas graves vivenciados nas situações sociais extremamente adversas e totalmente negligenciadas pelos Donos do Poder" (CONTIER, 2005, p. 6). Percebemos, em contrapartida, uma posição ofensiva, onde, de acordo com Félix Guattari e Sueli Rolnik, são evocados devires minoritários: "Um outro lado" que escapa aos processos de marginalização que atravessam a sociedade e representam "potencialidades de processos de transformação" (GUATTARI; ROLNIK, 2013, p. 88-90).

Através dessas expressões musicais, que constituem mundos, podemos falar em democracia. Consideramos que, por certa "meditação sobre a vida que esses seres escolheram" (RANCIÈRE, 2012b, p.140), constituem-se subjetividades políticas. Ao falarem de si, dos seus estilos de vida, há, pela estética, a constituição ética/política, em obras de artistas como Emicida, Racionais MC's $e$ Valesca Popozuda, por exemplo. Essa ética é discutida por Imannuel Kant, onde: "[...] estamos autorizados a pressupor universalmente em cada homem as mesmas condições subjetivas da faculdade do juízo que encontramos em nós [...]" (KANT, 2012, p. 144). Em outras palavras, quando os artistas refletem a respeito de suas vidas, de seus mundos, estão refletindo sobre quaisquer existências mundanas. Inspiramo-nos na ideia de "modo artista", como nas reflexões de Deleuze (1992), para pensar esta constituição ética na subjetivação política que avalia o modo de existência do indivíduo. Partimos, por esses estudos, da constatação de um duplo potencial nas artes - de bagunçar essas evidências da dominação e das destinações dos corpos - que contribuem na “instauração de dispositivos para mudar os tipos de sociedade” (GUATTARI; ROLNIK, 2013, p. 2223) e, dessa maneira, fazem a política que promove tensão na democracia consensual.

\section{A PARTILHA dO SENSÍVEL E A EFICÁCIA ESTÉTICA}

As artes, segundo Kant (2012), agem através do jogo livre das sensações. O juízo de gosto aqui é estético, isto é, por fundamento de determinação não possui nenhum conceito, tampouco o de 
um fim determinado. Entendemos, essencialmente através das discussões trazidas por Kant, que "na música este jogo vai de sensação do corpo a ideias estéticas (dos objetos para afetos) e destas então de volta ao corpo, mas com força conjugada" (KANT, 2012, p. 192). Sem pretensões de efeito ou de forma, a arte se apresenta com seu potencial transgressor, pois participa desse jogo e abre ao acontecimento novas possibilidades. Ainda com Kant, antes de qualquer mensagem que possa transmitir, a música transmite a vontade de fazer arte, simplesmente:

Não é o ajuizamento da harmonia de sons ou ocorrências espirituosas, que com sua beleza serve somente de veículo necessário, mas é a função vital promovida no corpo, o afeto, que move as vísceras e o diafragma, em uma palavra, o sentimento de saúde (que sem aquela iniciativa não se deixaria contrariamente sentir), que constituem o deleite que se encontra no fato de poder-se chegar ao corpo também pela alma e utilizar a esta como médico daquele (KANT, 2012, p. 192).

A discussão sobre o juízo de gosto levantada por Kant no final do século XVIII estabelece um conceito de gosto democrático onde: "Não pode haver nenhuma regra de gosto objetiva, que determine através de conceitos o que seja belo." O que determina a beleza é "o sentimento do sujeito", logo, o juízo de gosto é um "juízo estético” (KANT, 2012, p. 73), e não juízo de valor, como tentam nos convencer algumas pesquisas sobre a música que o Rap faz.

Friedrich Schiller, também em fins do século XVIII, anuncia, em suas cartas sobre $A$ educação Estética do Homem (1989), que “[...] para resolver na experiência o problema político é necessário caminhar através do estético, pois é pela beleza que se vai à liberdade" (SCHILLER, 1989, p. 24). Com Schiller, as artes não mais se delimitam: rompem-se suas hierarquias e, em seu limite, é a própria arte de viver. Para Rancière (2005), esse é o estado estético schilleriano: a pura suspensão, o momento de formação de uma humanidade específica. Seja pela arte, no trabalho do operário, do artesão ou no cuidado de si, o regime estético indica uma sociedade de artistas onde o homem é livre para realizar sua vontade em tudo o que faz.

Homens e mulheres desenvolvem a beleza pelo jogo livre, no regime estético das artes, no entanto, ainda que, assim como na arte, as forças humanas até hoje se formaram separadamente, o filósofo mais das vezes fez filosofia e o artista sua arte, entendemos que o artista deste período democrático, mesmo "enquadrado" em sua arte, como a música, o Rap; tem a possibilidade de agir também como um filósofo, por exemplo, ao traçar mapas do visível, relações entre modos do ser, modos do fazer e modos do dizer. O que está em jogo nestes enunciados são os corpos, suas posições e capacidades. Ocorre aí uma reconfiguração da partilha do sensível, que confunde "a funcionalidade dos gestos e dos ritmos adaptados aos ciclos naturais da produção, reprodução e submissão" (RANCIÈRE, 2005, p. 59). Arte e política demonstram que estão aí imbricadas, o artista é filósofo assim como o filósofo é uma artista. 
A arte em seu estado estético possui uma "eficácia estética", que significa "a suspensão de qualquer relação determinável entre a intenção do artista, a forma sensível apresentada num lugar de arte, o olhar de um espectador e um estado da comunidade" (RANCIÈRE, 2012a, p. 58). Eficácia da arte não em transmitir mensagens ou oferecer modelos de comportamento, como tenta nos convencer parte dos pesquisadores acadêmicos. A eficácia da arte em seu estado estético consiste “em disposições dos corpos, em recorte de espaços e tempos singulares que definem maneiras de ser" (RANCIÈRE, 2012a, p. 55). Os termos de Schiller, ainda que romanceados; assim como as imagens que apresentamos ao longo do artigo, nos trazem algumas pistas dessa eficácia:

Em meio ao reino terrível das forças e ao sagrado reino das leis, o impulso estético ergue imperceptivelmente um terceiro reino, alegre, de jogo e aparência, em que desprende o homem de todas as amarras das circunstâncias, libertando-o de toda a coerção moral ou física (SCHILLER, 1989, p.133).

Emicida, por exemplo, constrói o seu "reino de jogo e aparência", e por isso, sua obra é política. Essa política pode estar em qualquer lugar, e não necessariamente em um conteúdo "engajado" ou de crítica social. Pode estar numa cena de um videoclipe, quando a câmera foca na mão de uma criança que acaricia um cavalo branco (figura 3). A imagem não combina com o senso comum dos "excluídos sociais", que corrobora a noção de "engajamento", mas não é por isso que não contem crítica social, pois onde há uma captura dos dados sensíveis pelo artista e sua utilização na construção de outros lugares estranhos ao senso comum, podemos afirmar que há política. Com Rancière (2005), não se trata de utopia (o não lugar), mas heterotopias, ou seja, outros lugares construídos com o movimento dos corpos além dos saberes e poderes que o constituem; uma ética que demonstra um poder sobre si, um "cuidado de si” (FOUCAULT, 1985). Michel Foucault, no terceiro livro da História da sexualidade (1985), discorre sobre essa "invenção" grega que é a subjetivação - da qual já discorremos aqui - o que não significa um movimento de retorno aos gregos, mas uma forma de repensar as subjetivações hoje, pois estas estão em qualquer lugar onde há formação de indivíduos e nas artes, como no Rap, entendemos que há um intenso processo de subjetivação que contribui para as novas possibilidades de vida deste período democrático. 
Figura 3: O cavalo branco de Emicida

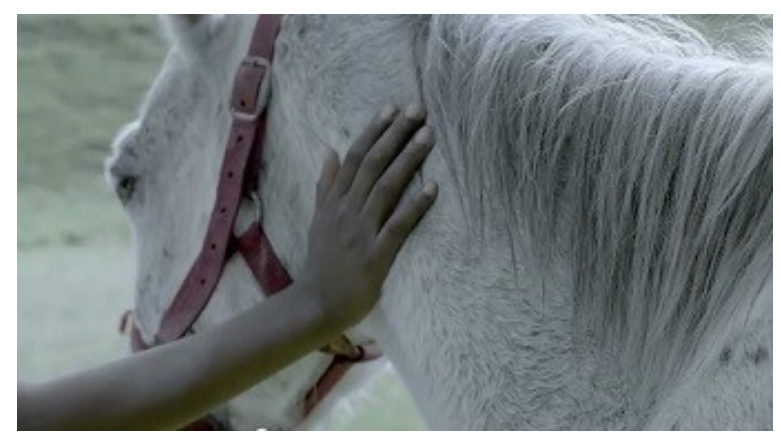

Fonte: EMICIDA: Levanta e anda Fifa 15 soundtrack (clipe oficial) part. Rael (2014).

Expomos, ainda, na sequência do debate, trecho do artigo de Contier onde define o que fazem os rappers:

\begin{abstract}
Os rappers não são heróis, em seu sentido romântico, mas a coragem de agir e falar sobre problemas da realidade e silenciados da vida cotidiana pela historiografia em suas canções marcadamente ritmadas e repetitivas levam a um novo tipo de inserção social, pois, agora, os despossuídos sociais começam a contar as suas próprias histórias não ajustadas a pensamentos políticos e ideológicos tradicionais, causando um certo "desconforto" entre setores das elites políticas e intelectuais tradicionais (CONTIER, 2005, p. 6).
\end{abstract}

Para discutir esse trecho, apresentamos duas imagens que podem nos falar ainda sobre a eficácia estética. Em uma delas, temos uma figura do filme "Cidade de Deus" (2002) e na sequência, uma fotografia da capa do álbum de Emicida. Com essas duas imagens, perguntamos: Qual delas diverte e qual politiza? Nossa resposta é impossível de ser respondida objetivamente, apenas subjetivamente. Essa situação já demonstra a fragilidade dos argumentos que enquadram o Rap como contestatório ou "engajado" por seu conteúdo discursivo de crítica e reflexão sociais. Seguindo com as imagens, façamos outra pergunta: Qual teria o potencial de causar mais desconforto nas "elites tradicionais"? Mudam-se os termos, mas a resposta ainda é a mesma. Ainda assim, podemos supor que a imagem do filme (figura 5) nos leva ao lugar dos "excluídos" sociais, já a capa do álbum nos remete a outro lugar que não o do senso comum defendido por autores como Contier, pois no lugar das "calças largas, lenços, bonés ou boinas na cabeça, correntes grossas no pescoço e no braço" (CONTIER, 2005, p. 2), vemos o reino de jogo e aparências de Emicida, onde o rapper, por que não, usa terno e gravata (figura 4). 
Figura 4: O "reino de jogo e aparência"
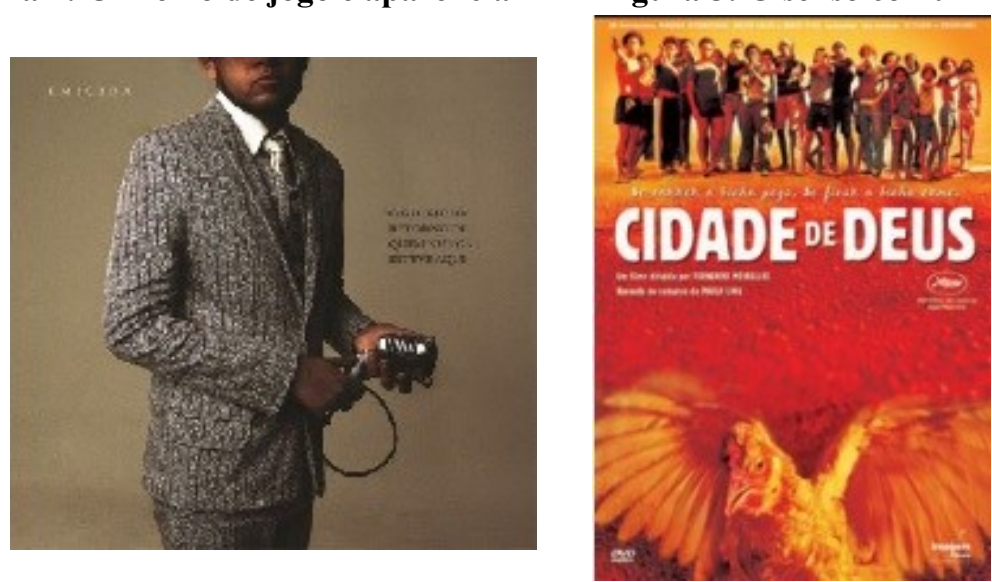

Fontes: CÉSAR, Ênio. Fotografia capa do álbum, Emicida: O Glorioso retorno de quem nunca esteve aqui (2013). CIDADE DE DEUS. Capa DVD. Direção: Fernando Meirelles (2002).

Em nossa abordagem, o efeito da arte relaciona-se com as "divisões de espaço e tempo e com os modos de apresentação sensível que instituem” antes do que a qualquer conteúdo. Esse efeito, todavia não é uma “contribuição calculável da arte para a ação política” (RANCIÈRE, 2012a, p. 63 64). Com Rancière, essa relação entre arte e política nos indica que o efeito da arte está justamente em não propor efeito:

Arte e política têm a ver uma com a outra como formas de dissenso, operações de reconfiguração da experiência comum do sensível. Há uma estética da política no sentido de que os atos de subjetivação política redefinem o que é visível, o que se pode dizer dele e que sujeitos são capazes de fazê-lo. Há uma política da estética no sentido de que as novas formas de circulação da palavra, de exposição do visível e de produção dos afetos determinam capacidades novas, em ruptura com a antiga configuração do possível. Há, assim, uma política da arte que precede as políticas dos artistas, uma política da arte como recorte singular dos objetos da experiência comum, que funciona por si mesma, independentemente dos desejos que os artistas possam ter de servir esta ou aquela causa (RANCIÈRE, 2012a, p. 66).

O poder do Rap em criar cenas de dissenso, antes de estar em seu conteúdo, está nessa disposição dos corpos fora de seus lugares na hierarquia. É o fato daqueles antes destinados pela filosofia política grega a phoné (o ruído sem lógica), filosofarem, é a inscrição desse demos na arte através de um elemento kratos que contribui para uma re-partilha do sensível. Foucault já algum tempo nos mostra que o poder "nunca está localizado aqui ou ali, nunca está nas mãos de alguns [...]. O poder funciona e se exerce em rede" (FOUCAULT, 1979, p. 183).

A ideia de partilha do sensivel que utilizamos é trabalhada por Rancière em suas obras, especialmente em $O$ desentendimento (1996) e A partilha do sensivel (2005). A partilha é "sempre uma distribuição polêmica das maneiras de ser e das 'ocupações' num espaço de possíveis" (RANCIÈRE, 2005, p. 63). O Rap não atua nessa partilha ao demonstrar a dominação da máquina sobre os corpos, como pressupõe o "engajamento", mas demonstrando, ao fazer arte, “[...] um corpo 
votado a outra coisa, que não a dominação" (RANCIÈRE, 2012a, p. 62). Antes de tudo, o fato daqueles que não deveriam falar, filosofarem, expõe o erro de contagem da filosofia grega no pensamento sobre a democracia, do qual falamos no início do artigo, pois essa contagem consiste na emissão sonora ser "ouvida como palavra, apta a enunciar o justo enquanto uma outra é apenas percebida como barulho que designa prazer ou dor, consentimento ou revolta" (RANCIÈRE, 1996, p. 36.)

\section{CONSIDERAÇÕES FINAIS}

Destarte, independente de suas motivações ou de seu conteúdo discursivo, a música, "por meio da invenção de uma instância de enunciação coletiva", contribui para a re-partilha dos dados sensíveis, anunciando que o "espaço das coisas comuns" (RANCIÈRE, 2012a, p. 60) não é mais o mesmo e que aqueles antes destinados ao trabalho da fábrica fazem uso do logos para discutir suas vidas. Uma vez que o poder não se impõe aos indivíduos, mas passa por eles, a arte em seu estado estético pode tocar a política, possibilitando assim a criação de cenas de dissenso. Entendemos que, pelo duplo poder das artes - em bagunçar as evidências de dominação e destinação dos corpos - podemos compreender esta época democrática. Propomos analisar essas cenas onde os corpos, antes destinados pelas hierarquias à obediência ou a "arte politizada", constroem outros lugares em um processo de subjetivação política.

\section{REFERÊNCIAS}

ARISTÓTELES. Poética. São Paulo: EDIPRO, 2011.

CÉSAR, Ênio. Emicida: O Glorioso retorno de quem nunca esteve aqui. 2013. Fotografia capa do álbum. Disponível em: <http://www.laboratoriofantasma.com/loja/CDs-DVDs/Emicida/emicidagrqnea-cd $>$. Acesso em: 14 ago. 15.

CIDADE de Deus. Direção: Fernando Meirelles. Produção: Andrea Barata Ribeiro e Maurício Andrade Ramos. Rio de Janeiro: O2 Filmes e Videofilmes, 2002. Capa DVD.

CONTIER, Arnaldo Daraya. O Rap Brasileiro e os Racionais MC's. In: Anais Simpósio Internacional do Adolescente. São Paulo. 1,. Maio 2005. Disponível em: $<\underline{\text { http://www.proceedings.scielo.br/scielo.php?script=sci arttext\&pid=MSC0000000082005000100 }}$ 010\&lng=pt\&nrm=iso\&tlng=pt $>$. Acesso em: 9 ago. 2015.

DELEUZE, Gilles. Conversações: (1972-1990). São Paulo: Ed. 34, 1992. 
EMICIDA: Levanta e anda Fifa 15 soundtrack (clipe oficial) part. Rael. Direção: Leandri HBL. Produção: Marcela Morgado e Lucas Rangel. Laboratório Fantasma Produções, 2014. Disponível em:

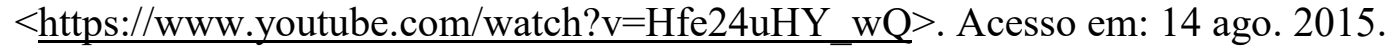

FOUCAULT, Michel. História da sexualidade 3: o cuidado de si. Rio de Janeiro: Edições Graal, 1985.

FOUCAULT, Michel. Microfísica do poder. Rio de Janeiro: Edições Graal, 1979.

GUATTARI, Félix. ROLNIK, Suely. Micropolítica: cartografias do desejo. Petrópolis - RJ: Vozes, 2013.

KANT, Immanuel. Crítica da faculdade do juízo. Rio de Janeiro: Forense Universitária, 2012.

MITTELDORF, Klaus. Racionais Mc's: Nada como um dia após o outro dia. 2012. Fotografia capa do álbum. Disponível em: < http://www.racionaisoficial.com.br/> Acesso em: 14 ago. 15.

OLIVEIRA, Roberto Camargos de. Música e Política: Percepções da vida social brasileira no Rap. 2011. 177 fls. Dissertação (Mestrado em História Social) - Universidade Federal de Uberlândia. Uberlândia, MG: 2011.

PLATÃO. A república: [ou sobre a justiça, diálogo político]. São Paulo: Martins Fontes - Selo Martins, 2014.

RANCIÈRE, Jacques. O desentendimento: política e filosofia. São Paulo: Ed. 34, 1996.

RANCIÈRE, Jacques. O mestre ignorante: cinco lições sobre a emancipação intelectual. Belo Horizonte: Autêntica Editora, 2013.

RANCIÈRE, Jacques. A partilha do sensível: estética e política. São Paulo: EXO/Ed. 34, 2005.

RANCIÈRE, Jacques. O espectador emancipado. São Paulo: Editora WMF Martins Fontes, 2012a.

RANCIÈRE, Jacques. As distâncias do cinema. Rio de Janeiro: Contraponto, 2012b.

RIGHI, Volnei José. RAP: Ritmo e Poesia. Construção identitária do negro no imaginário do RAP brasileiro. 2011. 515 fls. Tese (Doutorado em Literatura e Práticas Sociais) - Universidade de Brasília. Brasília, DF: 2011. 
SCHILLER, Friedrich. A educação estética do homem: numa série de cartas. São Paulo: Iluminuras, 1989.

SILVA, Rogério de Souza. A periferia pede passagem: Trajetória social e intelectual de Mano Brown. 2012. 302 fls. Tese (Doutorado em Sociologia) - Universidade Estadual de Campinas.

Campinas, SP: 2012.

VALESCA POPOZUDA: Beijinho no ombro (Official Music Video). Direção: Map Style. Pardal Produções, 2013. Disponível em: $<$ https://www.youtube.com/watch?v=73sbW7gjBeo $>$. Acesso em: 15 ago. 2015. 